\title{
PELATIHAN PENGGUNAAN DROPBOX UNTUK MANAJEMEN IKLAN KORAN BANJARMASIN POST GROUP PADA PT BANJARMASIN KARYA UTAMA
}

\author{
Nur Alamsyah, Wagino, dan Muhammad Rasyidan \\ Fakultas Teknologi Informasi, Universitas Islam Kalimantan MAB \\ Email : alam@fti.uniska-bjm.ac.id
}

\begin{abstract}
In the process of mounting an ad to be aired or published, an advertisement must be designed in advance as you wish installer and adapted to the size and content of the material you want to advertise. This time the results of advertising design sent from the office of PT BKU to Banjarmasin Post office (section Advertising Production) via email. Sending files advertising design via email often experience problems that the size of the design files exceed the maximum limit on the delivery of email which is only 25 $\mathrm{MB}$ only, while the size of the ad design can sometimes be up to $75 \mathrm{MB}$ and even 500 $\mathrm{MB}$, because if the size is too converted (under $25 \mathrm{MB}$ ), the results of design display can be blurred or broken, so they can let advertisers. Therefore, to overcome the above problems with the development of IT is now no such thing as Cloud Computing, which is an online file storage in the form of documents, images or video. DropBox is storage (storage) offers 2 GB of storage space for free. Unlike other file hosting, DropBox advantages is that it can be synchronized directly on the computer that we use (PC or Handphone), so that we can access the files that we save wherever we are, even while offline.
\end{abstract}

Keywords: Advertisment, Storage, Dropbox.

\section{PENDAHULUAN}

PT. Banjarmasin Karya Utama (PT. BKU) adalah perusahaan yang bergerak dibidang Advertising atau periklanan, memiliki 17 orang marketing (Account Executive /AE) yang mampu melayani para pelanggan atau pemasang iklan dimanapun berada, baik bertemu langsung, melalui telepon / sms atau melalui email.

PT BKU merupakan salah satu group dari Banjarmasin Post yang merupakan media koran terbesar di
Kalimantan Selatan. Koran Banjarmasin Post memiliki sebaran tidak hanya di banua enam (Banjarmasin, Banjarbaru, HSS, HSU, HST dan Tanjung) tapi tersebar luas hingga ke Kalimantan Tengah dan Kalimantan Timur. Selain koran Banjarmasin Post ada juga koran Metro Banjar dan Serambi ummah yang merupakan koran lokal seputar kota Banjarmasin, Banjarbaru dan Martapura.

Dalam sebuah media koran untuk menarik minat pembaca tidak hanya 
pada berita yang up to date tapi didalamnya ada juga iklan-iklan yang dipasang oleh pelanggan yang ingin mempromosikan produk, usaha atau peruahaannya baik lokal maupun nasional.

Iklan pada media koran mempunyai peranan penting dan sangat mempengaruhi dalam kelangsungan hidup sebuah koran, karena pendapatan terbesarnya adalah melalui iklan yang dipasang oleh pelanggan.

Selama ini para Marketing (AE) apabila mendapatkan order atau mendapatkan sebuah iklan mereka harus meluangkan waktu untuk kembali kekantor (Bagian Produksi Iklan) untuk didesain bahkan tidak jarang setelah selesai didesain mereka harus kembali mendatangi pelanggan, tidak jarang tempat pelanggan yang didatangi itu berada jauh dan memerlukan waktu. Sedangkan waktu untuk penayangan sebuah iklan itu sudah ditentukan yakni deadline sampai pukul 16.00 WITA.

\section{KHALAYAK SASARAN}

Seluruh karyawan PT Banjarmasin Karya Utama mulai dari direktur, sekretaris, administrasi, marketing dan bagian desain iklan.

\section{METODE}

Untuk mencapai tujuan yang diharapkan, maka pelaksanaan pelatihan penggunaan dropbox sebagai media penyimpanan cloud computing ini menggunakan 3 metode, yaitu:

1. Tutorial

Instruktur menjelaskan tentang dropbox dengan menggunakan alat bantu modul, powerpoint (presentasi) dan LCD agar peserta dapat lebih mudah memahami isi modul yang diberikan.

2. Praktek Mandiri

Setiap peserta melakukan praktek berupa proses menginstall, mengupload, mendownload dan menjalankan dropbox.

3. Tanya Jawab

Peserta dapat langsung bertanya kepada Tim Pengabdian pada masyarakat yang mendampingi mereka selama kegiatan berlangsung.

\section{HASIL DAN PEMBAHASAN}

Setelah mengikuti pelatihan penggunaan Dropbox untuk Manajemen Iklan Koran Banjarmasin Post Group pada PT BKU, sebagian besar peserta sangat antusias mengikuti kegiatan. 
Modul dalam pelatihan tersebut seperti dibawah ini :

\section{Registrasi Drop Box}

Syarat mutlak untuk memanfaatkan fasilitas Drop Box adalah telah memiliki fasilitas e-mail. Saat terhubung dengan internet, arahkan pada http://www.dropbox.com, hingga muncul tampilan seperti dibawah ini :

Langkah-langkahnya :

1. Scroll halaman kebawah sampai muncul kotak dialog seperti dibawah ini :

2. Arahkan cursor pada mulailah sekarang (membuat akun baru)

Mulailah sekarang
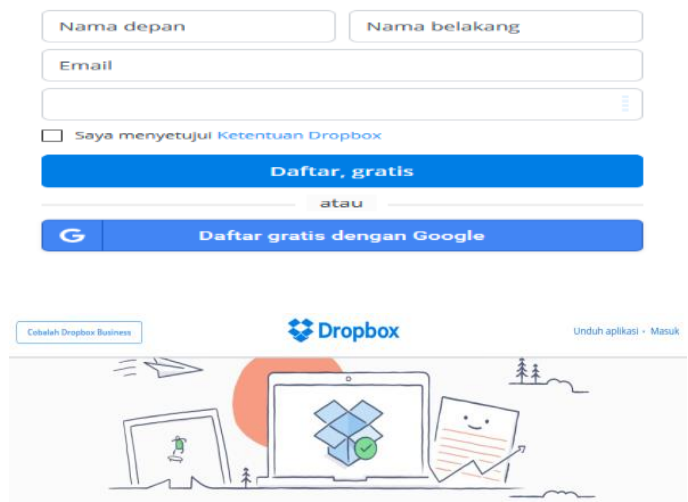

Dropbox bekerja sesuai cara Anda

Dapatkan semua fle Anda dari mana saja di perangkat apa saja, dan bagikar dengan slapa saja.

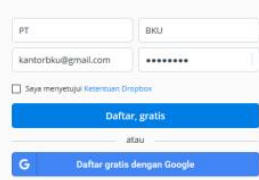

3. Isikan:

- FirstName

:Namadepan,misalnya:

PT

- LastName

:Namabelakang,misalny $\mathrm{a}: \mathrm{BKU}$

- Email

:Emailyangdimiliki,mis

alnya:kantorbku@gmail.com

- Password :Kata

kunci,misalnya:123456

4. Berikantandacentang padabagiansaya menyetujui .

5. Tekantombol Daftar Gratis

$\square$ Saya menyetujui Ketentuan Dropbox

\section{Daftar, gratis}

6. Setelahprosescreateaccountberhasi 1,secaraotomatissistemDropboxak anmeminta penggunauntukmelakukanprosesd ownload(unduh)programDropbox, sepertitampak padatampilandibawahini:

Bagus! Sekarang klik pemasang untuk menyelesaikannya.

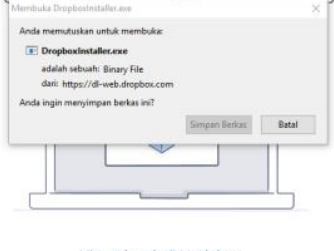

7. Klik tombol save file.

\section{InstalasiProgramDropbox(Micr osoftWindows)}

Setelahmelakukanprosespadatahapseb elumnya,tahapberikutnyaadalahprosesi nstalasi programDropBox.KliktombolRun. 
Dropbox Installer

Dropbox Installer is initializing, Please wait...

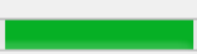

Langkah-langkahnya:

1. TekantombolInstalldan tunggu sampai

setelahprosesinstalasiselesai.

2. Kemudianmasukkanalamatemail yangakan digunakan seperticontoh dibawahini:

Set Up Dropbox

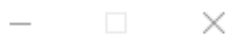

kantorbku@gmail.com

Sign in

G Sign in with Google
Set Up Dropbox
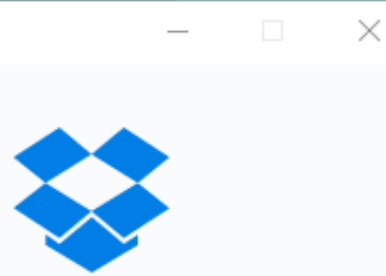

Congratulations!

Your Dropbox was successfully installed

\section{Open my Dropbox}

Advanced settings

3. Ikuti saja langkah-langkahnya sampai finish

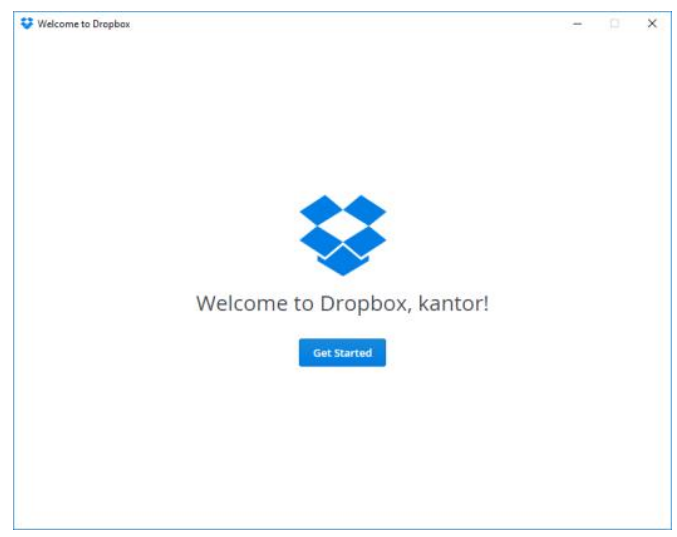



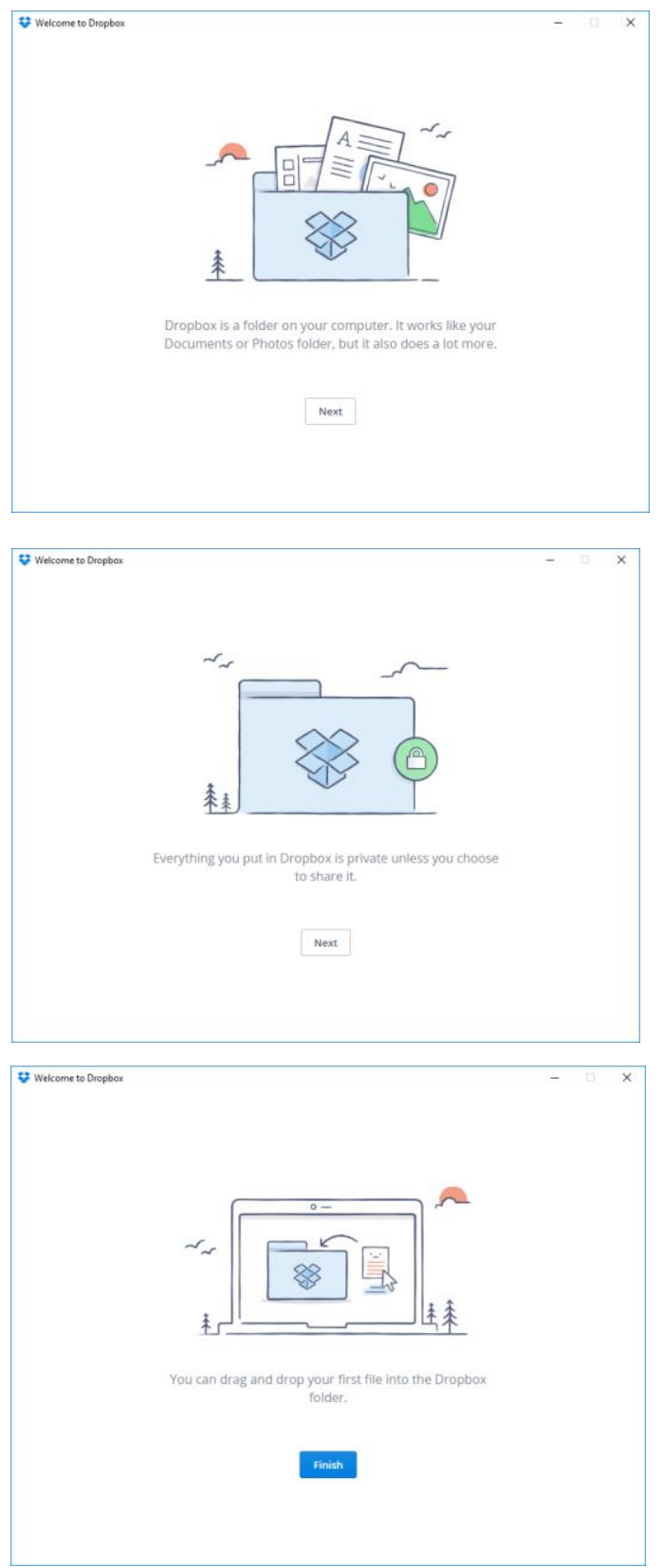

4. Padalangkahke3dari5langkahakandi tunjukkaniconyangterletakdipojokk ananbawah.

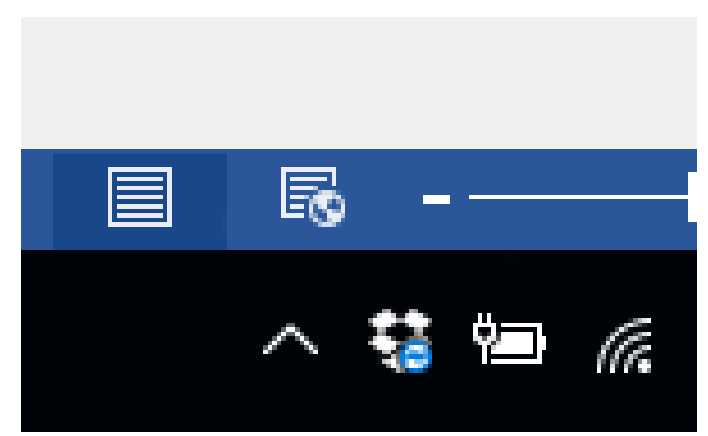

5. Padatampilanterakhirnyaadalahseba gaiberikut:

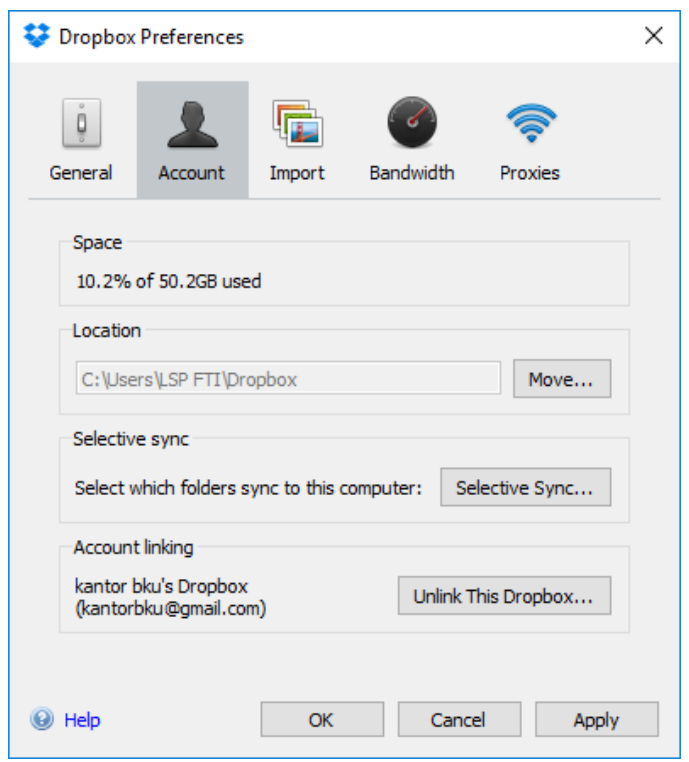

Sampai dengan tahap ini, Pengguna telah berhasil menginisialisasi komputer untuk dapat digunakanbertukardatamenggunakanD ropbox.

Penggunadapatmembuatfolder,meletak kanfilepadaDropboxtersebut.Setiapper ubahanyang terjadipadaDropboxyangadapadakomp uter,bilasuatusaatkomputertersebutonli ne/

terhubungdenganinternet,makaakansec araotomatistersinkronisasi.

Untukmelihathasilsinkronisasinya,langk ah-langkahnya:

1. Pastikan pengguna terhubung dengan internet.

2. Buka browser internet, kemudian ketikkan : http://www.dropbox.com 
3. Lakukan proses sign-in, isikan :

- Email, adalah email yang telah diregistrasikan untuk dropbox

- Password, adalah kode kunci yang telah dibuat saat registrasi dropbox.

4. Tekan tombol Sign-in untuk melanjutkan.

5. Arahkan cursor mouse pada menu Dropbox. Sehingga akan tampak seperti tampilan dibawahini:

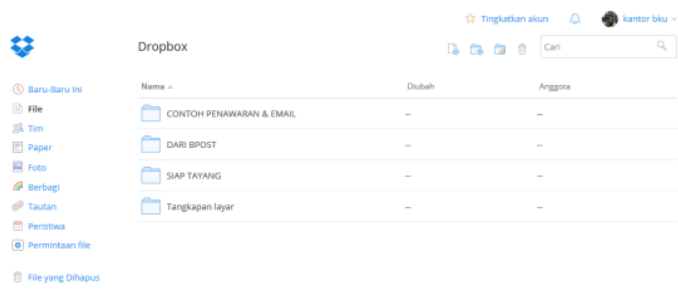

\section{FOTO KEGIATAN}
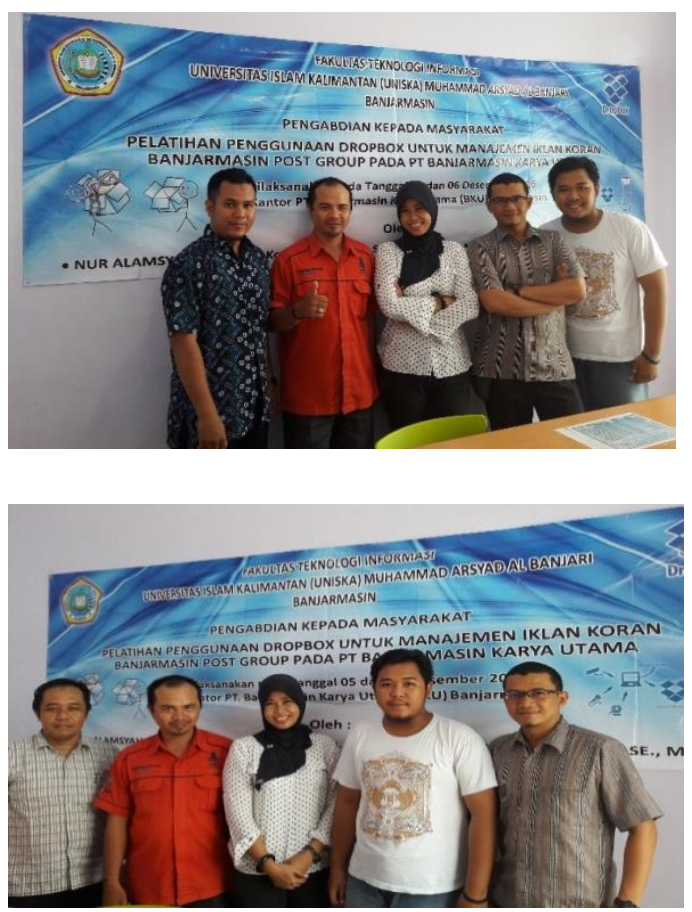
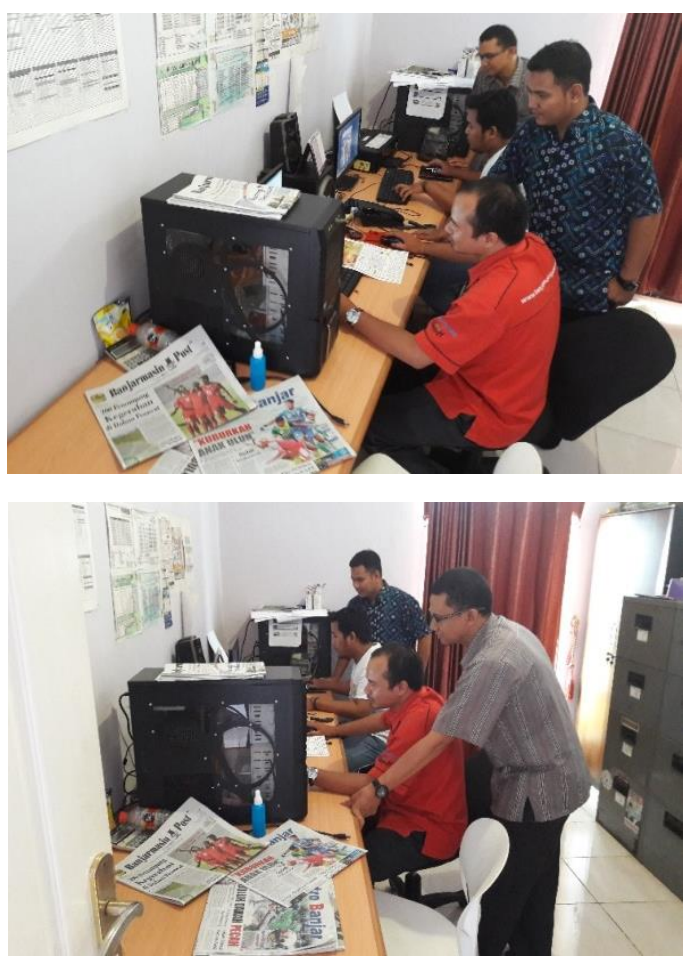

\section{KESIMPULAN}

Dengan dilaksanakannya kegiatan pengabdian masyarakat oleh Dosen Fakultas Teknologi Informasi Uniska di PT Banjarmasin Karya Utama, maka seluruh karyawan dapat menerapkan secara maksimal penggunaan media penyimpanan Dropbox sebagai penunjang dan sebagai solusi dalam pengiriman file yang berukuran besar.

\section{DAFTAR PUSTAKA}

Alex Budiyanto, 2012, Pengantar Cloud Computing, CloudIndonesiA.ORG Jogjakarta.

Iwan Sofana,, 2012, Cloud computing: teori dan praktik (OpenNebula, VMware, dan Amazon AWS), INFORMATIKA, Bandung. 
Ilmu sebelas, 2012, Ayo share File di DrfopBox diambil kembali dari http://ilmusebelas.blogspot.co.id/2012/04/c ara-mudah-upload-file.html (diakses 7 September 2016)

Adiba Kamalia, 2013 CARA MENGGUNAKAN DROPBOX diambil kembali dari http://ilmukomputer.org/2013/06 /22/cara-menggunakan-dropbox/ (diakses 6 September 2016)

berguruSEO,2014 Panduan Cara Install dan Menggunakan Dropbox di Komputer

http://berguruseo.blogspot.com/ 2014/12/panduan-cara-installdan-menggunakan-dropbox-di- komputer.html (diakses 7 September 2016)

Indonesia pintar, 2014 Panduan cara menggunakan Dropbox diambil dari

https://www.youtube.com/watch ?v=E0W-LUrlpI0 (diakses 7 Sept 2016)

Nadiar AS, 2015 Cara Menggunakan Dropbox dan Install Dropbox pada Komputer, http://arsip.pabelog.com/caramenggunakan-dropbox-installdropbox/ (diakses 7 September 2016).

Dropbox, 2016 Apakah Dropbox itu? https://www.dropbox.com/id/hel p/6642 (diakses 6 September 2016) 